Published in final edited form as:

Brain Behav Immun. 2009 January ; 23(1): 10-15. doi:10.1016/j.bbi.2008.06.007.

\title{
Neuroendocrine modulation of cancer progression
}

\author{
Guillermo N. Armaiz-Pena ${ }^{1,3}$, Susan K. Lutgendorf ${ }^{4}$, Steve W. Cole ${ }^{5}$, and Anil K. Sood ${ }^{1,2}$ \\ 1 Department of Gynecologic Oncology, University of Texas M. D. Anderson Cancer Center, Houston, Texas \\ 2 Department of Cancer Biology, University of Texas M. D. Anderson Cancer Center, Houston, Texas \\ 3 Program in Cancer Biology, University of Texas Health Science Center Graduate School of Biomedical \\ Sciences, Houston, Texas
}

4 Departments of Psychology, Obstetrics and Gynecology and Urology, University of Iowa, Iowa City, Iowa

5 Division of Hematology-Oncology, Department of Medicine, UCLA School of Medicine, Los Angeles, California

\begin{abstract}
Clinical and animal studies now support the notion that psychological factors such as stress, chronic depression and lack of social support might promote tumor growth and progression. Recently, cellular and molecular studies have started to identify biological processes that could mediate such effects. This review provides a mechanistic understanding of the relationship between biological and behavioral influences in cancer and points to more comprehensive behavioral and pharmacological approaches for better patient outcomes.
\end{abstract}

\section{Keywords}

Cancer; behavioral stress; angiogenesis; metastasis

\section{Introduction}

The notion that psychosocial factors can affect malignant progression has long been suspected (Reiche et al., 2004). Clinical and epidemiological studies have recognized that specific psychosocial factors, such as stress, chronic depression, and lack of social support are risk factors for the development and progression of cancer. However, as a whole, data supporting a relationship between behavioral risk factors and cancer initiation have been inconsistent. In contrast, behavioral factors are more reliably found to predict differences in tumor progression (Antoni et al., 2006). For example, some recent studies have not found a relationship between stressful life events (Duijts et al., 2003) or personality (Bleiker et al., 2008) and development of cancer, although several others have reported such relationships, particularly in situations of severe life stress (Lillberg et al., 2003; Price et al., 2001). A process in which severe stressful situations accumulate resulting in a positive influence on cancer initiation might explain the differences observed between studies. Additionally, in some of these studies, the quality of

Correspondence and reprint requests: Dr. Anil K. Sood, Professor, Director, Ovarian Cancer Research, Departments of Gynecologic Oncology and Cancer Biology, The University of Texas, M. D. Anderson Cancer Center, 1155 Herman Pressler, Unit 1362, Houston, TX 77030, Phone: 713-745-5266, Fax: 713-792-7586, e-mail: asood@mdanderson.org.

Publisher's Disclaimer: This is a PDF file of an unedited manuscript that has been accepted for publication. As a service to our customers we are providing this early version of the manuscript. The manuscript will undergo copyediting, typesetting, and review of the resulting proof before it is published in its final citable form. Please note that during the production process errors may be discovered which could affect the content, and all legal disclaimers that apply to the journal pertain. 
self-reported measures varies, and longitudinal assessment of factors such as depression and stress is rare. Clinical studies focused on the relationship between behavior and the progression of already-diagnosed cancers have found that factors such as suppression of negative emotions, hopelessness, denial, and lack of social support are associated with poorer survival (Antoni et al., 2006). These clinical data parallel results from animal-based studies demonstrating that experimentally-imposed stress can modulate cancer progression (Thaker and Sood, 2007). Recent mechanistic studies have started to uncover specific signaling pathways that are activated through the neuroendocrine stress response, resulting in promotion of tumor growth and metastasis. Even though this review will focus on the neuroendocrine, cellular, and molecular processes that are capable of mediating the relationship between behavioral factors and cancer growth and progression, important glucocorticoid-mediated pathways will remain outside of the scope of this review. Before proceeding to explore neuroendocrine mechanisms on cancer progression, we begin this review with a brief summary of neuroendocrine responses to stressors and the cancer initiation and metastasis processes.

\section{Neuroendocrine stress response}

Stress reflects an intricate process involving environmental and psychosocial factors that set off multiple information processing pathways in the central nervous system (CNS) and periphery. These pathways elicit fight or flight stress responses in the autonomic nervous system (ANS), or defeat/withdrawal responses that are produced by the hypothalamicpituitary-adrenal axis (HPA) (Glaser and Kiecolt-Glaser, 2005). Activation of these pathways normally prepares a person to endure a threat; however, under chronic stress, most organs are negatively affected by extended exposure to glucocorticoids and catecholamines (Antoni et al., 2006). These changes can produce harmful health consequences such as increased risk for cardiac disease, slower wound healing, and increased risk for infection. In the past decade, it has become increasingly clear that chronic changes in neuroendocrine dynamics can also alter various physiological processes that play a role in tumor pathogenesis.

HPA responses are a result of hypothalamic production of corticotrophin-releasing factor and arginine vasopressin, both of which promote the secretion of pituitary hormones, such as adrenocorticotropic hormone (ACTH), enkephalins, and endorphins. ACTH release stimulates the adrenal cortex to release glucocorticoids such as cortisol. Glucocorticoids can influence growth, metabolism and immune function, and play a critical role in regulating basal function and stress reactivity among different organs. Sympathetic nervous system (SNS) activation and subsequent release of catecholamines (principally norepinephrine and epinephrine) from sympathetic neurons and the adrenal medulla mediate ANS stress responses. Catecholamine levels have been found to be elevated in individuals who experience acute or chronic stress, and mediate ANS influences on cardiac, respiratory, vascular and other organ systems (Antoni et al., 2006). Multiple stressors are linked with alterations in the HPA and/or ANS including marital disruption, bereavement, depression, chronic sleep disruption, severe trauma and posttraumatic stress disorder (Glaser and Kiecolt-Glaser, 2005). In this review article, we will consider the potential influences of stress-induced neuroendocrine responses on cancer initiation and progression.

\section{Cancer Initiation}

Multiple studies suggest that human tumorigenesis is part of a multi-step process. Each of these sequential steps reflects genetic changes that cause progressive alteration of normal human cells into malignant cells. The process in which normal cells convert into a cancerous state seems to require various rate-limiting steps that include genetic and epigenetic changes. For example, to acquire tumorigenicity, human cells must overcome two barriers, replicative senescence and cellular crisis, each limiting the cell lifespan in an effort to achieve 
immortalization. These barriers are regulated by telomere shortening and by the RB and p53 tumor suppressor pathways (Hanahan and Weinberg, 2000). In a landmark paper, Hanahan and Weinberg proposed six essential alterations in cell physiology that mediate malignant growth: 1) self-sufficiency in growth signals, 2) insensitivity to growth-inhibitory signals, 3 ) evasion of programmed cell death, 4) limitless replicative potential, 5) sustained angiogenesis, and 6) tissue invasion and metastasis (Hanahan and Weinberg, 2000). Each of these gained capabilities is a direct result of normal host defense evasion that results in the promotion of malignant cell growth. Viral infections in some tumors, such as Kaposi's sarcoma and cervical cancer, play an important role in gaining some of these capabilities by delivering new genes into the cell. Additionally, carcinogens can cause physical damage to cellular DNA that alters the expression or function of human genes. Interestingly, a recent animal study suggested that chronic stress can increase the susceptibility to UV-induced squamous cell carcinoma by suppressing type 1 cytokines and protective T-cells and by enhancing regulatory/suppressor $\mathrm{T}$ cell numbers (Saul et al., 2005). Ultimately, it does not matter whether tumors are initiated by viral infections or carcinogens; the end product is a somatic cell that posses enhanced growth capacity and an increased ability to thrive within the body by acquiring new genetic changes. This process of tumor initiation is often facilitated by bi-directional signaling interactions between a developing tumor cell and the surrounding cells of the tumor microenvironment (e.g., vascular endothelial cells, macrophages and other immune cells, connective tissues, and basement membranes) (Langley and Fidler, 2007). Local inflammatory signaling is a microenvironmental dynamic that is believed to support the growth of initiated tumor cells (Coussens and Werb, 2002).

\section{Metastasis}

After a cell acquires tumorigenic potential and has established its microenvironment, cancer metastasis can occur after cells begin spreading from the primary tumor to distant organs. This process is followed by persistent growth at those sites. Frequently, metastases form clinically relevant lesions that result in host death due to resistance to conventional therapy. The metastatic cascade consists of several rate-limiting sequential steps, the first of which involves the recruitment of blood vessels. Vascularization must be established for a tumor mass to exceed $1 \mathrm{~mm}$ in diameter and also provides a pathway for dissemination of metastatic cells. To escape the primary tumor site, a tumor cell must be able to invade through surrounding tissue (e.g., basement membrane), detach from the primary tumor mass, embolize into the blood stream, arrest in capillary beds of organs, extravasate out of the blood stream and into parenchymal tissue, evade host defenses (e.g., immune responses) and continue to grow. If the cell is not able to complete any of the steps in the metastatic cascade, the process is aborted (Langley and Fidler, 2007).

Cancers from distinct primary tissue sites exhibit organ-specific metastatic patterns. At the end of the 19th century, British scientist Stephen Paget showed that different types of primary cancers established metastases in distinct target organs, and he ingeniously proposed that these patterns were due to the dependence of the cancer cell on the metastatic site's microenvironment. He called this the "seed and soil" hypothesis (Langley and Fidler, 2007). If the regulation of metastasis is considered in terms of a balance between growth stimulating factors from tumor and host cells versus inhibitory signals, successful metastasis requires that the balance be shifted toward increased levels of stimulatory signals. Even though Paget's observations date back more than one hundred years, the mechanistic role of the tumor microenvironment has only recently begun to be uncovered. Tumor growth and progression is a direct result of a constant crosstalk between various cell types within the tumor and the tumor stroma, which serves as the tumor supporting tissue. The tumor stroma possesses specific extracellular matrix, cellular components such as fibroblasts, immune and inflammatory cells, and blood-vessel cells. As a result, the signaling interaction between tumor and stroma 
contributes to the development and maintenance of primary and secondary tumor growth (Langley and Fidler, 2007). The organ microenvironment also has the ability to alter geneexpression patterns in cancer cells and thereby alter tumor cell behavior and growth. For example, studies with breast cancer cells have shown that environmental influences can potentially dominate over the tumor genotype to revert cancer cells to a non-malignant phenotype, even while the cells remain genotypically malignant (Bissell, 2007). Recent studies also show that chemokines and their receptors may contribute to organ-specific metastasis. For example, cancer cells often express chemokine receptors, and ligands for these receptors are usually found at high levels in target sites for cancer metastasis (Langley and Fidler, 2007).

\section{Neuroendocrine effects on cancer progression pathways}

\subsection{Primary tumor growth and metastasis development}

At both primary and metastatic sites, activation of autocrine, paracrine, and/or endocrine pathways can influence tumor cell proliferation by shifting the net balance of positive and negative signals (Langley and Fidler, 2007). Most data seem to suggest that catecholamines repress normal cell proliferation, such as slowing keratinocyte growth, resulting in impaired wound healing in the context of stress (Flaxman and Harper, 1975). In breast cancer, some studies in model systems have linked $\beta_{2}$-adrenergic receptor activation to increased tumor growth and progression. However, other studies show $\beta$-adrenergic inhibition of human tumor cell growth in an animal model via blockade of the Raf-1/Mek-1/Erk1/2 pathway (Carie and Sebti, 2007). Another study utilized a neuroblastoma model to show that norepinephrine inhibited cancer cell growth, specifically in cells that expressed the dopamine transporter. In cells that had dopamine uptake, the ratio of cells in $\mathrm{G}_{0} / \mathrm{G}_{1}$ was greatly increased after treatment with norepinephrine (Pifl et al., 2001).

$\beta_{2}$-adrenergic receptors may also facilitate the effects of other stimuli on cell proliferation in cancer. For example one recent study showed that these receptors contribute to nicotineinduced activation of the protein kinase C/Erk1/2/cyclooxygenase 2 pathway, leading to enhanced gastric cancer cell proliferation (Shin et al., 2007). The cAMP responsive elementbinding (CREB) protein is a key transcriptional factor that is activated by various signaling pathways in response to external stimuli such as stress hormones. CREB also plays an important role in tumor cell proliferation, migration, angiogenesis, and apoptosis inhibition (Jean and Bar-Eli, 2000). Thus, $\beta$-adrenergic receptor signaling might interact with other CREB activators to modulate molecular processes involved in tumor progression. Viral infections are key co-factors in the initiation of approximately $20 \%$ of human tumors, and all major human tumor-associated viruses have been found to be activated by either beta-adrenergic or glucocorticoid-mediated signaling pathways (Antoni et al., 2006). For example, Human herpesvirus 8, which induces Kaposi's sarcoma, bears a cAMP response element in the promoter of a key viral transcription factor. $\beta$-adrenergic stimulation of the viral host cell induces CREB-mediated expression of viral oncogenes and growth factors. Epstein-Barr virus and high-risk variants of the human papilloma virus are similarly subject to activation by glucocorticoids (Antoni et al., 2006).

In a prostate carcinoma model, treatment with cAMP agonists resulted in epithelial prostate cancer cells acquiring neuroendocrine characteristics (Cox et al., 1999). These characteristics were represented by dense core granules in the cytoplasm, the extension of neuron-like processes, loss of mitogenic activity, and expression of various neuroendocrine markers. The presence of these neuroendocrine-like cells has been linked to poor prognosis in prostate cancer patients (Cohen et al., 1991). These neuroendocrine-like cells have minimal proliferation rates, but appear to promote proliferation of surrounding cells by paracrine stimulation. 


\subsection{Adhesion to extracellular matrix}

The tumor cell ability to invade and metastasize to distant organs depends on the cell adhesive capacity to the extracellular matrix within tissues. The extracellular matrix is primarily composed of type I and IV collagens, laminins, heparin sulfate proteoglycan, fibronectin, and other noncollagenous glycoproteins (Sood et al., 2006). Integrins serve as membrane-bound receptors that mediate extracellular matrix-cell interaction. The process by which matrix components regulate adhesion is not clearly understood, but it is known that cAMP has the ability to regulate activity of the adhesion-mediating small GTPases RhoA and Rac through the activation of protein kinase A (Mercurio and Rabinovitz, 2001). Recent studies also show that the exchange factor directly activated by cAMP (Epac) is also involved in integrinmediated cell adhesion and cell-cell junction formation. Consistent with these observations, recent data show that the $\beta$-agonist isoproterenol promotes ovarian cancer cell spreading and adhesion to laminin-5 in an Epac dependent fashion and promotes adhesion to a fibronectin matrix in a cAMP mediated Epac-Rap1 pathway (Bos, 2006). Thus, stress hormones may promote cancer cell-matrix attachments. This mechanism would be particularly relevant for ovarian cancer where cancer cells shed off the primary tumor and then implant at various peritoneal sites.

\subsection{Cancer cell migration and invasion}

To reach blood vessels or lymphatics, tumor cells must penetrate host stroma, including the basement membrane. The process by which tumor cells penetrate the host basement membrane consists of multiple steps that involve attachment, matrix dissolution, motility, and then actual penetration (Langley and Fidler, 2007). There are now several lines of evidence suggesting that stress hormones can promote tumor cell movement and invasion. For example, in a breast cancer model, norepinephrine induced not only a chemotactic response, but also promoted chemokinetic migration (Drell et al., 2003). Norepinephrine can also promote migration in a phospholipase $\mathrm{C} \gamma$ and protein kinase $\mathrm{C} \alpha$ dependent manner. Our group has recently examined the role of catecholamines and glucocorticoids on the invasive potential of ovarian cancer cells, and matrix metalloproteinases that are important for tumor cell penetration of extracellular matrix (Sood et al., 2006). Norepinephrine concentrations that would mimic those in stress conditions significantly increased the in vitro invasiveness of ovarian cancer cells. Epinephrine also promoted the invasive potential of ovarian cancer cells, but cortisol failed to have a significant effect. These effects were blocked by a $\beta$-adrenergic receptor antagonist.

Additionally, norepinephrine increased the in vitro production of MMP- 2 and MMP- 9 by tumor cells, and pharmacologic inhibition of MMPs blocked norepinephrine mediated increase in tumor cell invasion. Similar findings have been demonstrated in a nasopharyngeal carcinoma model; catecholamines increased the invasive potential by increasing MMP-2 and MMP-9 levels (Yang et al., 2006). These findings provide direct experimental evidence that at the in vitro level, stress hormones can promote ovarian cancer cell invasion.

\subsection{Tumor associated angiogenesis}

New vessel growth is a critical step that enables a solid tumor to grow beyond $1 \mathrm{~mm}$ in diameter. Additionally, metastasis requires recruitment of nearby blood vessels to permeate the tumor (Langley and Fidler, 2007). Recently, it has been found that stress hormones may promote angiogenic mechanisms in human tumors. Vascular endothelial growth factor (VEGF), an important cytokine that drives angiogenesis, has been shown to be upregulated by norepinephrine through the use of beta adrenergic receptor/cAMP/protein kinase A (PKA) signaling pathway in adipose tissue, nasopharyngeal cancer cells and in two ovarian cancer cell lines (Lutgendorf et al., 2003; Yang et al., 2006). The effect of norepinephrine with regard to VEGF stimulation was abolished by a beta-blocker, and mimicked by agonists and thought to be mediated via $\beta$-adrenergic receptors (Thaker et al., 2006). Furthermore, norepinephrine 
has been found to have the ability to modulate the expression of VEGF in a $\beta_{2}$-adrenergic receptor mediated fashion in non-solid tumors, such as multiple myeloma (Yang et al., 2008).

In vivo cancer models have confirmed in vitro observations regarding the effects of stress on tumor angiogenesis. In an ovarian cancer orthotopic model, chronic stress induced by daily restraint, resulted in higher levels of tissue catecholamines, increased tumor burden, and a more invasive phenotype. Angiogenesis, as quantified by microvessel density counts, was significantly increased in tumor samples taken from stressed mice. Moreover, these same samples had elevated VEGF mRNA and protein levels. Continuous infusion of a non-selective $\beta$-blocker partially abrogated the effects of stress on tumor growth and progression, suggesting that $\beta$-adrenergic receptors play an important role in stress mediated tumor growth (Thaker et al., 2006). Parallel to these findings, clinical data have demonstrated that there is an association between higher levels of social support and lower serum VEGF levels in ovarian cancer patients (Lutgendorf et al., 2002).

Interleukin 6 (IL-6) is another key cytokine that plays a key role in tumor progression and angiogenesis (Nilsson et al., 2005). Experimentally, gelfoam sponge assays showed that IL-6 is capable of increasing microvessel density (Nilsson et al., 2005). Clinically, individuals who provide care to a spouse with dementia have been shown to exhibit increased circulating IL-6 levels and ovarian cancer patients that had elevated IL-6 levels had a poorer prognosis (KiecoltGlaser et al., 2003). In ovarian cancer patients, social support was correlated with lower IL-6 levels, both in peripheral circulation and in ascites, indicating that relationships of IL-6 with biobehavioral factors are also observed at the tumor level, not just in peripheral blood (Costanzo et al., 2005). Recent experimental studies using an ovarian cancer model showed that norepinephrine significantly increased IL-6 mRNA and protein expression. Specifically, this increase was due to catecholamine-mediated regulation of IL-6 at the transcriptional level. Additionally, norepinephrine induced IL-6 production in ovarian carcinoma cells was regulated by a $\beta$-adrenergic receptor/Src tyrosine kinase pathway (Nilsson et al., 2007).

The signal transducer and activator of transcription factor-3 (STAT-3) is activated by growth factors and cytokines, such as IL-6 and VEGF and has been found to promote angiogenesis and suppress apoptosis (Antoni et al., 2006). It is known that cytokines such as IL-6 can contribute to tumor growth and progression through the activation of STAT3. Recent studies have sought to determine whether stress hormones induce the expression, cellular localization and activation of STAT3 in an ovarian cancer model. Specifically, norepinephrine and epinephrine were found to activate STAT3, promote translocation to the nucleus and binding to DNA. These effects on STAT3 were mediated by $\beta$-adrenergic receptors and PKA signaling and were independent of IL-6. Taken together, studies suggest that stress-mediated tumor progression may result, in part, through STAT3 activation of downstream effector pathways (Landen et al., 2007).

\subsection{Cancer cell survival}

The continuation of the metastatic process depends on the ability of the tumor cell to survive and avoid apoptosis (Langley and Fidler, 2007). It has been shown that dopamine and norepinephrine can trigger apoptosis via a $\mathrm{G}$ protein-mediated signaling cascade in neuroblastoma cells, but not in lung carcinoma cells (Chan et al., 2007). More importantly, epinephrine reduced the sensitivity of prostate and breast cancer cells to apoptosis through PKA-dependent BAD phosphorylation that was mediated by $\beta$-adrenergic receptor activation (Sastry et al., 2007). Furthermore, catecholamines may also partner with glucocorticoids to promote cancer growth. For example, cortisol increased the isoproterenol-induced cAMP and $\beta$-adrenergic receptor accumulation on the cellular membrane and substantially increased the effects of IL- $1 \alpha$, IL-1 $\beta$, and TNF- $\alpha$ in lung carcinoma cells (Nakane et al., 1990). Although, large scale human studies are needed, a provocative epidemiological study showed reduction 
in prostate cancer risk among patients that used beta blockers, suggesting a key role for $\beta$ adrenergic receptors in development of prostate cancer (Perron et al., 2004).

\subsection{Other stress mediators}

Prolactin, oxytocin, dopamine and substance $\mathrm{P}$ are among other hormones that are affected by stress (Antoni et al., 2006). Prolactin has been shown to promote tumor cell growth and survival of breast and other cancer cells (Antoni et al., 2006). Various epidemiological studies suggested that a correlation exists between prolactin levels and breast cancer risk factors such as parity and age at menarche. The majority of breast cancer cell lines express the prolactin receptor. In these cell lines, prolactin has limited trophic effects. Additionally, prolactin has been demonstrated to promote proliferation in prostate and endometrial cancer cells (Antoni et al., 2006). Besides inducing proliferation, prolactin may also serve as an anti-apoptotic agent since it inhibits mammary tumor cell apoptosis by Akt stimulation (Richert, 2001).

Oxytocin can inhibit growth of epithelial tumors and those that arise from nervous or bone origin, but the hormone has a growth promoting effect on trophoblast and other tumors (Cassoni et al., 2001). Dopamine, an important member of the catecholamine family, since it is a precursor in the synthesis of catecholamines, is one of the major neurotransmitters in the mammalian brain and plays an important role in the periphery (Thaker and Sood, 2007). It has been suggested that chronic stress exposure leads to reduced dopamine levels. Several lines of evidence suggest that dopamine can inhibit tumor cell growth in different types of cancers, including neuroblastoma, breast, melanoma, and head and neck (Thaker and Sood, 2007). Growth reduction may be a result of activation of dopamine receptors or dopamine autooxidation resulting in the generation of reactive oxygen species. However, recent studies show that dopamine may reduce tumor growth by other mechanisms. For example, studies with in vivo models have shown that dopamine can inhibit tumor growth by blocking the vascular permealizing and angiogenic activities of VEGF (Basu et al., 2001). Furthermore, it was shown that dopamine acts through D2 dopamine receptors to promote endocytosis of VEGF receptor 2 , which is critical for promoting angiogenesis (Basu et al., 2001). Additional in vivo models showed that both tumor size and vessel density are lower in rats with a hyperactive dopaminergic system, suggesting a link between dopaminergic activity, angiogenesis, and tumor growth and progression (Thaker and Sood, 2007). Substance $\mathrm{P}$ is a peptide in the neurokinin family and is normally found in the central and peripheral nervous systems. It plays a role in stress reactions, anxiety and depression (Kramer et al., 1998). Although its role in cancer progression is not clearly understood, substance $\mathrm{P}$ is known to promote the migration of multiple cell lines and is a potent chemoattractant for squamous cell lung cancer cells (Esteban et al., 2006).

\section{Summary}

Cancer initiation, progression and metastasis are intricate processes that depend on various steps including genetic alterations, growth/proliferation, vascularization, invasion, embolization, and survival/evasion of apoptosis. When a tumor is established, its survival, growth, and metastatic spread heavily depend on interactions with its microenvironment. In this review, we have turned our attention toward the interplay between biobehavioral factors and cancer initiation and metastasis. Despite evidence linking stress and cancer progression, studies evaluating the direct effects of stress hormones on cell proliferation are inconclusive. Even though recent advances are encouraging, our understanding of mechanisms that would explain these relationships is still vague and needs to be expanded.

Behavioral stress effects on tumor initiation and progression are complex and should be analyzed in the context of relevant microenvironment biology. New studies should offer opportunities that would open the door for innovative therapeutic interventions based on 
behavioral and pharmacological approaches aimed at tumor-supporting neuroendocrine processes. This new approach should be designed to undermine the support network that tumors use as fuel for growth and spread. As discussed in this review, $\beta$-blockers have been shown to abrogate many deleterious stress effects on malignant growth. Some clinical studies have shown lower cancer incidence among patients treated with $\beta$-blockers, whereas in other subjects the cancer risk was neutral (Perron et al., 2004). Important advances have been made in understanding the influence of behavioral factors on cancer initiation and progression, but further research is needed to completely understand the complex underlying signaling that is driving malignant growth. As cancer treatment evolves to patient-specific approaches, such findings will be of great value as novel patient-specific and comprehensive intervention strategies are integrated or used in combination with conventional therapies.

\section{Acknowledgements}

This work was funded through the NCI F31CA126474 Fellowship for Minority Students award to GNA-P; NIH grants (CA109298 and CA110793), and the U.T. M. D. Anderson SPORE in ovarian cancer (P50CA083639) to AKS.

\section{References}

Antoni MH, Lutgendorf SK, Cole SW, Dhabhar FS, Sephton SE, McDonald PG, Stefanek M, Sood AK. The influence of bio-behavioural factors on tumour biology: pathways and mechanisms. Nat Rev Cancer 2006;6:240-248. [PubMed: 16498446]

Basu S, Nagy JA, Pal S, Vasile E, Eckelhoefer IA, Bliss VS, Manseau EJ, Dasgupta PS, Dvorak HF, Mukhopadhyay D. The neurotransmitter dopamine inhibits angiogenesis induced by vascular permeability factor/vascular endothelial growth factor. Nat Med 2001;7:569-574. [PubMed: 11329058]

Bissell MJ. Modelling molecular mechanisms of breast cancer and invasion: lessons from the normal gland. Biochem Soc Trans 2007;35:18-22. [PubMed: 17212581]

Bleiker EM, Hendriks JH, Otten JD, Verbeek AL, van der Ploeg HM. Personality factors and breast cancer risk: a 13-year follow-up. J Natl Cancer Inst 2008;100:213-218. [PubMed: 18230799]

Bos JL. Epac proteins: multi-purpose cAMP targets. Trends Biochem Sci 2006;31:680-686. [PubMed: 17084085]

Carie AE, Sebti SM. A chemical biology approach identifies a beta-2 adrenergic receptor agonist that causes human tumor regression by blocking the Raf-1/Mek-1/Erk1/2 pathway. Oncogene 2007;26:3777-3788. [PubMed: 17260025]

Cassoni P, Marrocco T, Deaglio S, Sapino A, Bussolati G. Biological relevance of oxytocin and oxytocin receptors in cancer cells and primary tumors. Ann Oncol 2001;12(Suppl 2):S37-39. [PubMed: 11762350]

Chan AS, Ng LW, Poon LS, Chan WW, Wong YH. Dopaminergic and adrenergic toxicities on SK-N$\mathrm{MC}$ human neuroblastoma cells are mediated through $\mathrm{G}$ protein signaling and oxidative stress. Apoptosis 2007;12:167-179. [PubMed: 17136323]

Cohen RJ, Glezerson G, Haffejee Z. Neuro-endocrine cells--a new prognostic parameter in prostate cancer. Br J Urol 1991;68:258-262. [PubMed: 1913066]

Costanzo ES, Lutgendorf SK, Sood AK, Anderson B, Sorosky J, Lubaroff DM. Psychosocial factors and interleukin-6 among women with advanced ovarian cancer. Cancer 2005;104:305-313. [PubMed: 15954082]

Coussens LM, Werb Z. Inflammation and cancer. Nature 2002;420:860-867. [PubMed: 12490959]

Cox ME, Deeble PD, Lakhani S, Parsons SJ. Acquisition of neuroendocrine characteristics by prostate tumor cells is reversible: implications for prostate cancer progression. Cancer Res 1999;59:38213830. [PubMed: 10447001]

Drell, TLt; Joseph, J.; Lang, K.; Niggemann, B.; Zaenker, KS.; Entschladen, F. Effects of neurotransmitters on the chemokinesis and chemotaxis of MDA-MB-468 human breast carcinoma cells. Breast Cancer Res Treat 2003;80:63-70. [PubMed: 12889599] 
Duijts SF, Zeegers MP, Borne BV. The association between stressful life events and breast cancer risk: a meta-analysis. Int J Cancer 2003;107:1023-1029. [PubMed: 14601065]

Esteban F, Munoz M, Gonzalez-Moles MA, Rosso M. A role for substance P in cancer promotion and progression: a mechanism to counteract intracellular death signals following oncogene activation or DNA damage. Cancer Metastasis Rev 2006;25:137-145. [PubMed: 16680578]

Flaxman BA, Harper RA. In vitro analysis of the control of keratinocyte proliferation in human epidermis by physiologic and pharmacologic agents. J Invest Dermatol 1975;65:52-59. [PubMed: 239072]

Glaser R, Kiecolt-Glaser JK. Stress-induced immune dysfunction: implications for health. Nat Rev Immunol 2005;5:243-251. [PubMed: 15738954]

Hanahan D, Weinberg RA. The hallmarks of cancer. Cell 2000;100:57-70. [PubMed: 10647931]

Jean D, Bar-Eli M. Regulation of tumor growth and metastasis of human melanoma by the CREB transcription factor family. Mol Cell Biochem 2000;212:19-28. [PubMed: 11108132]

Kiecolt-Glaser JK, Preacher KJ, MacCallum RC, Atkinson C, Malarkey WB, Glaser R. Chronic stress and age-related increases in the proinflammatory cytokine IL-6. Proc Natl Acad Sci U S A 2003;100:9090-9095. [PubMed: 12840146]

Kramer MS, Cutler N, Feighner J, Shrivastava R, Carman J, Sramek JJ, Reines SA, Liu G, Snavely D, Wyatt-Knowles E, Hale JJ, Mills SG, MacCoss M, Swain CJ, Harrison T, Hill RG, Hefti F, Scolnick EM, Cascieri MA, Chicchi GG, Sadowski S, Williams AR, Hewson L, Smith D, Carlson EJ, Hargreaves RJ, Rupniak NM. Distinct mechanism for antidepressant activity by blockade of central substance P receptors. Science 1998;281:1640-1645. [PubMed: 9733503]

Landen CN Jr, Lin YG, Armaiz Pena GN, Das PD, Arevalo JM, Kamat AA, Han LY, Jennings NB, Spannuth WA, Thaker PH, Lutgendorf SK, Savary CA, Sanguino AM, Lopez-Berestein G, Cole SW, Sood AK. Neuroendocrine modulation of signal transducer and activator of transcription-3 in ovarian cancer. Cancer Res 2007;67:10389-10396. [PubMed: 17974982]

Langley RR, Fidler IJ. Tumor cell-organ microenvironment interactions in the pathogenesis of cancer metastasis. Endocr Rev 2007;28:297-321. [PubMed: 17409287]

Lillberg K, Verkasalo PK, Kaprio J, Teppo L, Helenius H, Koskenvuo M. Stressful life events and risk of breast cancer in 10,808 women: a cohort study. Am J Epidemiol 2003;157:415-423. [PubMed: 12615606]

Lutgendorf SK, Cole S, Costanzo E, Bradley S, Coffin J, Jabbari S, Rainwater K, Ritchie JM, Yang M, Sood AK. Stress-related mediators stimulate vascular endothelial growth factor secretion by two ovarian cancer cell lines. Clin Cancer Res 2003;9:4514-4521. [PubMed: 14555525]

Lutgendorf SK, Johnsen EL, Cooper B, Anderson B, Sorosky JI, Buller RE, Sood AK. Vascular endothelial growth factor and social support in patients with ovarian carcinoma. Cancer 2002;95:808815. [PubMed: 12209725]

Mercurio AM, Rabinovitz I. Towards a mechanistic understanding of tumor invasion--lessons from the alpha6beta 4 integrin. Semin Cancer Biol 2001;11:129-141. [PubMed: 11322832]

Nakane T, Szentendrei T, Stern L, Virmani M, Seely J, Kunos G. Effects of IL-1 and cortisol on betaadrenergic receptors, cell proliferation, and differentiation in cultured human A549 lung tumor cells. J Immunol 1990;145:260-266. [PubMed: 2162889]

Nilsson MB, Armaiz-Pena G, Takahashi R, Lin YG, Trevino J, Li Y, Jennings N, Arevalo J, Lutgendorf SK, Gallick GE, Sanguino AM, Lopez-Berestein G, Cole SW, Sood AK. Stress hormones regulate interleukin-6 expression by human ovarian carcinoma cells through a Src-dependent mechanism. J Biol Chem 2007;282:29919-29926. [PubMed: 17716980]

Nilsson MB, Langley RR, Fidler IJ. Interleukin-6, secreted by human ovarian carcinoma cells, is a potent proangiogenic cytokine. Cancer Res 2005;65:10794-10800. [PubMed: 16322225]

Perron L, Bairati I, Harel F, Meyer F. Antihypertensive drug use and the risk of prostate cancer (Canada). Cancer Causes Control 2004;15:535-541. [PubMed: 15280632]

Pifl C, Zezula J, Spittler A, Kattinger A, Reither H, Caron MG, Hornykiewicz O. Antiproliferative action of dopamine and norepinephrine in neuroblastoma cells expressing the human dopamine transporter. Faseb J 2001;15:1607-1609. [PubMed: 11427501]

Price MA, Tennant CC, Smith RC, Butow PN, Kennedy SJ, Kossoff MB, Dunn SM. The role of psychosocial factors in the development of breast carcinoma: Part I. The cancer prone personality. Cancer 2001;91:679-685. [PubMed: 11241234] 
Reiche EM, Nunes SO, Morimoto HK. Stress, depression, the immune system, and cancer. Lancet Oncol 2004;5:617-625. [PubMed: 15465465]

Richert, MDK.; Anderson, SM. Mechanisms underlying constitutive action of Akt in breast cancer cell lines. Proceedings of the 83rd annual meeting of the endocrine society; 2001. p. 551

Sastry KS, Karpova Y, Prokopovich S, Smith AJ, Essau B, Gersappe A, Carson JP, Weber MJ, Register TC, Chen YQ, Penn RB, Kulik G. Epinephrine protects cancer cells from apoptosis via activation of cAMP-dependent protein kinase and BAD phosphorylation. J Biol Chem 2007;282:14094-14100. [PubMed: 17353197]

Saul AN, Oberyszyn TM, Daugherty C, Kusewitt D, Jones S, Jewell S, Malarkey WB, Lehman A, Lemeshow S, Dhabhar FS. Chronic stress and susceptibility to skin cancer. J Natl Cancer Inst 2005;97:1760-1767. [PubMed: 16333031]

Shin VY, Wu WK, Chu KM, Koo MW, Wong HP, Lam EK, Tai EK, Cho CH. Functional role of betaadrenergic receptors in the mitogenic action of nicotine on gastric cancer cells. Toxicol Sci 2007;96:21-29. [PubMed: 17003101]

Sood AK, Bhatty R, Kamat AA, Landen CN, Han L, Thaker PH, Li Y, Gershenson DM, Lutgendorf S, Cole SW. Stress hormone-mediated invasion of ovarian cancer cells. Clin Cancer Res 2006;12:369375. [PubMed: 16428474]

Thaker PH, Han LY, Kamat AA, Arevalo JM, Takahashi R, Lu C, Jennings NB, Armaiz-Pena G, Bankson JA, Ravoori M, Merritt WM, Lin YG, Mangala LS, Kim TJ, Coleman RL, Landen CN, Li Y, Felix E, Sanguino AM, Newman RA, Lloyd M, Gershenson DM, Kundra V, Lopez-Berestein G,

Lutgendorf SK, Cole SW, Sood AK. Chronic stress promotes tumor growth and angiogenesis in a mouse model of ovarian carcinoma. Nat Med 2006;12:939-944. [PubMed: 16862152]

Thaker PH, Sood AK. Neuroendocrine influences on cancer biology. Semin Cancer Biol 2007;18:164170. [PubMed: 18201896]

Yang EV, Donovan EL, Benson DM, Glaser R. VEGF is differentially regulated in multiple myelomaderived cell lines by norepinephrine. Brain Behav Immun 2008;22:318-323. [PubMed: 17981009]

Yang EV, Sood AK, Chen M, Li Y, Eubank TD, Marsh CB, Jewell S, Flavahan NA, Morrison C, Yeh $\mathrm{PE}$, Lemeshow S, Glaser R. Norepinephrine up-regulates the expression of vascular endothelial growth factor, matrix metalloproteinase (MMP)-2, and MMP-9 in nasopharyngeal carcinoma tumor cells. Cancer Res 2006;66:10357-10364. [PubMed: 17079456]

Brain Behav Immun. Author manuscript; available in PMC 2010 January 1. 


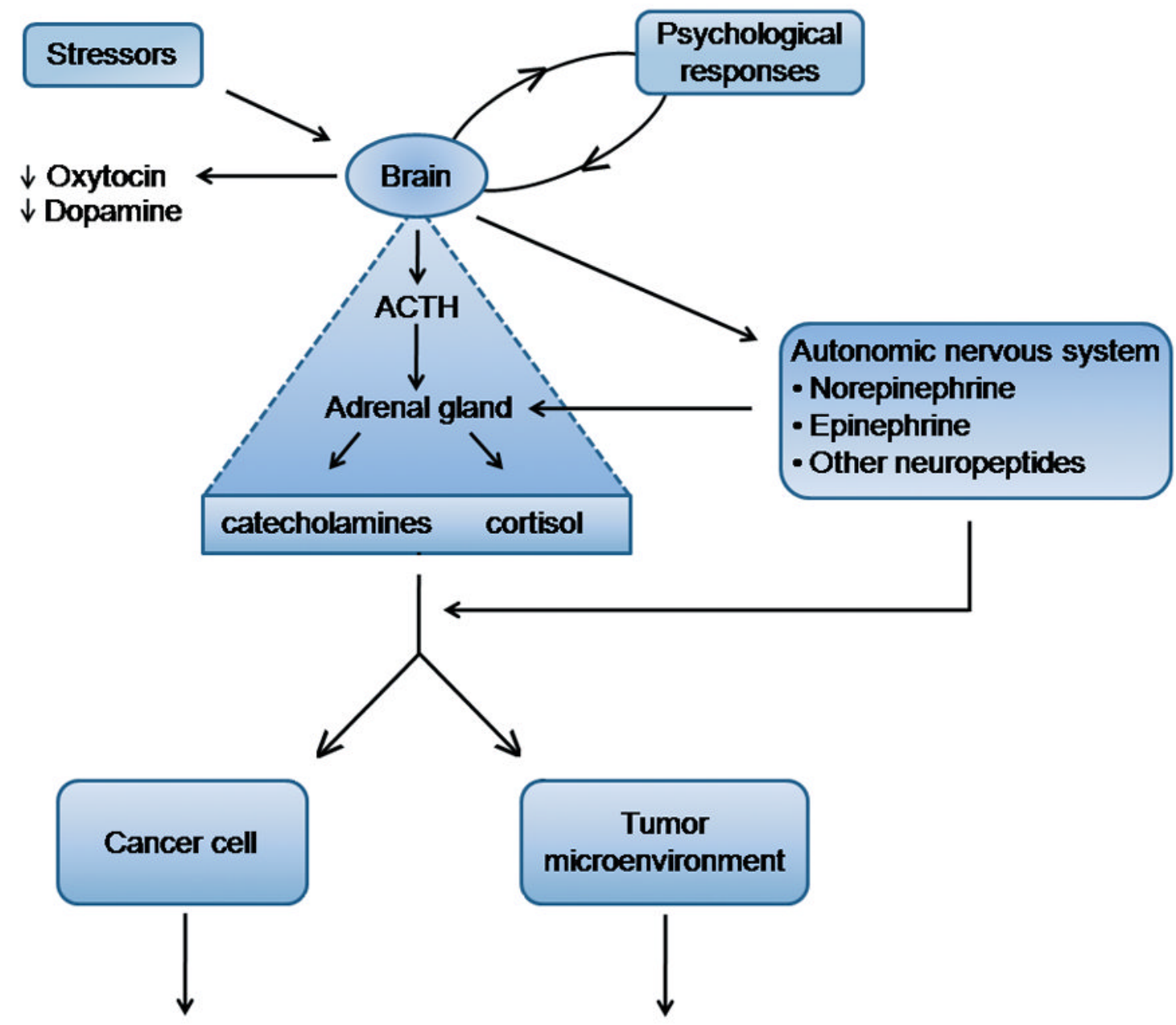

\section{$\uparrow$ Migration and invasion $\uparrow$ Proteases (MMPs) Altered DNA repair}

\section{$\uparrow$ Angiogenesis/pro-angiogenic factors (VEGF, IL6, STAT3)}

Figure 1.

Effect of stress-associated factors on the tumor microenvironment. The stress response involves the central nervous system's ability to perceive a threat. This response results in activation of the autonomic nervous system and the hypothalamic-pituitary-adrenal axis causing the release of catecholamines, glucocorticoids and other stress hormones from the adrenal gland, brain and sympathetic nerve terminals. These factors can alter the activity of various components of the tumor microenvironment. Effects include alteration of DNA repair mechanisms, enhanced tumor growth, increased cell migration and invasion, and stimulation of angiogenesis by increasing production of angiogenic factors. Collectively, these downstream effects result in the establishment of a favorable microenvironment that will support tumor initiation, growth and progression. 